\title{
Effects of maternal dioxin exposure on newborn size at birth among Japanese mother-infant pairs
}

\author{
Kenji Tawara $\cdot$ Muneko Nishijo $\cdot$ Ryumon Honda $\cdot$ \\ Shoko Maruzeni · Toshio Seto · Teruhiko Kido · \\ Shigeru Saito $\cdot$ Hideaki Nakagawa
}

Received: 28 July 2008/Accepted: 9 October 2008/Published online: 8 November 2008

(C) The Japanese Society for Hygiene 2008

\begin{abstract}
Objective Maternal exposure to dioxins [polychlorinated dibenzo-p-dioxins (PCDDs) and dibenzofurans (DFs)] during pregnancy is known to affect infant growth and neurodevelopment in humans and animals. The aim of this study was to investigate the relationship between newborn size and the concentration of dioxin isomers in breast milk and to subsequently evaluate the potential toxicity of each dioxin isomer among mothers living in sea coast areas who are at a high risk of contamination due to a high consumption of fish.

Methods A total of 75 milk samples were obtained within 1 month of delivery from Japanese mothers living in the
\end{abstract}

K. Tawara $\cdot$ M. Nishijo $(\bowtie) \cdot$ S. Maruzeni $\cdot$ H. Nakagawa

Department of Public Health,

Kanazawa Medical University, 1-1 Daigaku,

Uchinada, Ishikawa 920-0293, Japan

e-mail: ni-koei@kanazawa-med.ac.jp

R. Honda

Department of Social and Environmental Health,

Kanazawa Medical University, 1-1 Daigaku,

Uchinada, Ishikawa 920-0293, Japan

T. Seto

Department of Obstructive and Gynecology,

Kanazawa Medical Hospital, 1-1 Shimo-Ishibiki,

Kanazawa, Ishikawa 920-8650, Japan

T. Kido

School of Health Sciences, Kanazawa University,

5-11-80 Kodatsuno, Kanazawa,

Ishikawa 920-0942, Japan

S. Saito

Department of Obstructive and Gynecology,

Faculty of Medicine, University of Toyama,

2630 Sugitani, Toyama 930-0194, Japan coastal areas of the Japan Sea. The relationships between the levels of seven dioxins and ten furan isomers in maternal breast milk, measured by high-resolution-gas chromatography/mass spectrometry, and the birth size of newborns, which is related to fetal growth, were investigated after adjustment for confounding factors.

Results The concentrations of $1,2,3,6,7,8-\mathrm{HxCDD}$ (hexachlorodibenzo-p-dioxin), 2,3,4,7,8-PeCDF (pentachlorodibenzofuran), 2,3,4,6,7,8-HxCDF, and three dioxin toxic equivalent (TEQ) levels (PCDDs-TEQ, PCDFs-TEQ, and total-TEQ) in maternal breast milk were inversely correlated to newborn length even after adjustment for gestational weeks, infant sex, and maternal age and height. These isomers were abundant among the 17 isomers tested and reflected the TEQ levels. Only 2,3,7,8-tetrachlorodibenzo- $p$-dioxin $(2,3,7,8$-TCDD), the most toxic isomer, was negatively correlated with newborn head circumference, even after adjustment for gestational weeks, infant birth weight, and other confounding factors.

Conclusions Based on our results, fetal growth may be influenced by maternal total exposure to dioxins, but only exposure to $2,3,7,8$-TCDD would appear to possibly affect fetal head size during pregnancy.

Keywords Birth size $\cdot$ Breast milk $\cdot$ Dioxins . Newborn $\cdot 2,3,7,8$-Tetrachlorodibenzo-p-dioxin

\section{Introduction}

Polychlorinated dibenzo-p-dioxins (PCDDs) and dibenzofurans (DFs), commonly referred to as dioxins, are well-known unintentional hazardous by-products of numerous industrial processes, such as waste incineration, pesticide manufacturing, and pulp and paper bleaching. 
The effects of environmental exposure to PCDDs/DFs on subsequent generations of the general population have been a focus of public concern since these substances have been suggested to be environmental endocrine disruptors.

Based on studies of pregnant women who were accidentally exposed to high levels of polychlorinated biphenyls (PCBs) and PCDDs/DFs, it has been suggested that maternal exposure to dioxins can affect fetal growth and infant development. A well-known example of accidental exposure is the incident at Seveso, Italy in 1976 [1], and evidence for an alteration in the infant sex ratio in the offspring of the residents of Seveso with high serum 2,3,7,8-tetrachlorodibenzo- $p$-dioxin (2,3,7,8-TCDD) levels (range 104-2340 pg/g-lipid) was reported in a 10-year follow-up survey from 1976 to 1985 [2, 3]. Other occurrences include exposure of Vietnamese populations to the herbicide and defoliant Agent Orange, which contains high levels of dioxins, between 1962 and 1971 as a result of spraying for military purposes. An increase in the incidence of birth defects in the offspring of Vietnamese and U.S. veterans assigned to the defoliated areas has been recorded [4]. In Japan and Taiwan, "Oil disease" (Japanese, "Yusho", Taiwanese, "Yu-Cheng") occurred when cooking oil contaminated with very high levels of PCBs and PCDDs/DFs was accidently consumed. Yu-Cheng children born to exposed mothers had low birth weights [5] and delayed cognitive development [6].

In a Dutch population-based study, residents with low or background exposure to dioxins, showed lower infant birth weights [7]. In this study, dioxins in the breast milk were quantified as the dioxin toxic equivalent (TEQ), which was then multiplied by the duration in weeks of breast feeding to obtain an index of postnatal exposure. However, fat in breast milk is mainly derived from mobilized adipose or hepatic lipids [8], and dietary measures did not influence the dioxin levels in breast milk [9], suggesting that dioxins in breast milk indicate the dioxin level in the mother's fat stores before and during pregnancy. In addition, it is easier to analyze all $17 \mathrm{PCDD} / \mathrm{DF}$ isomers in breast milk samples and compare these with the levels found in serum samples because of the much higher fat content in breast milk.

It is believed that seafood is a major source of exposure to dioxins in Japan. Traditional eating habits based on the consumption of rice and fish products are deeply rooted among the residents of the Japan Sea coastal areas where a high fish intake can lead to exposure to dioxins. Accordingly, we examined the relationship between newborn birth size, which is related to fetal growth, and dioxin isomer levels in maternal breast milk as an indicator of maternal PCDD/DF exposure. Our aim was to evaluate the health effects of each dioxin isomer among Japanese residents living in sea coast areas at a risk of dioxin exposure.

\section{Subjects and methods}

Subjects and data collection

The study area was Hokuriku District, which is located in a coastal area of the Japan Sea. Residents of this area predominantly consume the traditional Japanese diet based on rice and seafood. We recruited Japanese mother-infant pairs, who stayed in the hospital after delivery and cooperated in donating their milk samples and providing clinical information before and during delivery. The mothers was asked to complete a self-administered questionnaire on parity, clinical history of pregnancy, height, weight before pregnancy and weight before delivery, smoking habit, alcohol consumption, dietary habits, and occupational history, and the information was confirmed by maternity nurses. No differing characteristics related to socioeconomic status, nutrition, and health management were observed among the mothers. Table 1 shows some of the clinical and population characteristics provided by the questionnaire. Of the 75 women who participated in the study, $72 \%$ were homemakers, and only two women smoked during pregnancy. The gestational age and body build of all the infants at birth are also shown in Table 1 . Three pre-term $(<37$ gestational weeks) babies and seven low birth weight $(<2500 \mathrm{~g})$ babies were included in this study. Breast milk samples were collected into polypropylene tubes from the mothers in the first month after delivery and stored at $-20^{\circ} \mathrm{C}$ until analysis.

Informed consent for this study was obtained from the subjects in the appropriate manner, and the study was approved by the institutional ethics board for epidemiological studies at Kanazawa Medical University.

\section{Analysis of PCDDs/DFs in milk samples}

Fat in breast milk was extracted from $10 \mathrm{ml}$ of each sample, and the fat content was determined by the method reported by Patterson et al. [10]. After 2,3,7,8-substituted ${ }^{13} \mathrm{C}$-labeled PCDDs/DFs as internal standards were added to the fat extract, a series of purification operations consisting of alkali digestion and chromatography on a multilayered column of silica gel and on a single-layered column of activated carbon dispersed on silica gel was carried out to separate and collect the PCDDs/DFs [11]. The final extract was concentrated by evaporation to $20 \mu \mathrm{l}$. Quantification was performed by a gas chromatograph equipped with a high-resolution mass spectrometer (HR-GC/MS; MStation-JMS700, JEOL), operating in the selected ion monitoring (SIM) mode. The gas chromatograph (HP6980; Hewlett-Packard, Palo Alto, CA) was equipped with an ENV-5MS column. The detection limit of $<0.02 \mathrm{pg} / \mathrm{g}$ on a lipid basis was achieved at a signal-noise $(\mathrm{S} / \mathrm{N})$ ratio 
Table 1 Population characteristics of 75 motherinfant pairs
BMI, Body mass index

${ }^{\text {a }}$ Values are given as the mean. Values presented in parenthesis are the standard deviation followed by the minimummaximum values

\begin{tabular}{|c|c|}
\hline Study population characteristics & Values \\
\hline \multicolumn{2}{|l|}{ Mothers } \\
\hline Age $^{\mathrm{a}}$ (years) & $29.8(4.0,20-38)$ \\
\hline Height $^{\mathrm{a}}(\mathrm{cm})$ & $158.0(4.6,147-171)$ \\
\hline Weight before pregnancy ${ }^{\mathrm{a}}(\mathrm{kg})$ & $52.5(7.8,41-96)$ \\
\hline BMI before pregnancy ${ }^{a}$ & $21.0(2.7,17.0-34.0)$ \\
\hline Weight $(\mathrm{kg})$ before delivery ${ }^{\mathrm{a}}$ & $61.5(7.8,44.5-98)$ \\
\hline BMI before delivery $^{\mathrm{a}}$ & $24.6(2.7,19.8-34.7)$ \\
\hline Primipara, $n(\%)$ & $40(53.3)$ \\
\hline Delivery by cesarian section, $n(\%)$ & $9(12.0)$ \\
\hline Smoking habit before pregnancy, $n(\%)$ & $11(14.7)$ \\
\hline Smoking habit during pregnancy, $n(\%)$ & $2(2.7)$ \\
\hline Alcohol consumption before pregnancy, $n(\%)$ & $24(32.0)$ \\
\hline Alcohol consumption during pregnancy, $n(\%)$ & $6(8.0)$ \\
\hline Occupation (house-wife), $n(\%)$ & $54(72.0)$ \\
\hline \multicolumn{2}{|l|}{ Infants } \\
\hline Gestational age (weeks) ${ }^{\mathrm{a}}$ & $38.9(1.5,34-42)$ \\
\hline Sex, number of boys, (sex ratio) & $37(0.97)$ \\
\hline Length $^{\mathrm{a}}(\mathrm{cm})$ & $49.5(2.0,42-53)$ \\
\hline Weight $^{\mathrm{a}}(\mathrm{g})$ & $3,075(440.5,2028-4052)$ \\
\hline Chest circumference $^{\mathrm{a}}(\mathrm{cm})$ & $32.0(2.1,27-37.5)$ \\
\hline Head circumference $^{\mathrm{a}}(\mathrm{cm})$ & $33.2(1.4,30-36)$ \\
\hline
\end{tabular}

of 3. In addition to the respective concentrations of the 17 isomers, TEQs of PCDDs, PCDFs, and total dioxins were calculated for each sample, with reference to the international Toxicity Equivalent Factor (TEF) of the World Health Organization (WHO-TEF 1998) [12]. All concentrations of each isomer and TEQs were determined in a lipid base.

\section{Statistical analysis}

Data were statistically analyzed using the SPSS (ver. 11.0) software package for Windows (SPSS, Chicago, IL). Logarithmetric transformation of the measured values of PCDDs/DFs was performed to improve normality. We analyzed the measurements of all breast milk samples regardless of collection period because there was no significant difference in the PCDDs/DFs levels between the samples collected within 1 month of delivery and those collected on postpartum days 5-8. A value equal to half of the detection limit was used for subjects with a level under the detection limit. Spearman's correlations were performed to determine the association between newborn build and PCDD/DF levels in breast milk, and that between the newborn and mother's variables. Multiple linear regression analysis was used to estimate associations between newborn build and PCDDs/DFs in maternal breast milk after adjustment for confounding factors. A significance level of $P<0.05$ was used for all statistical tests.

\section{Results}

Levels of PCDDs/DFs in breast milk

Table 2 shows the levels of seven PCDD isomers and ten PCDF isomers in breast milk. In particular, high levels of PCDD isomers OCDD $(1,2,3,4,6,7,8,9$-octachlorodibenzo$p$-dioxin) and 1,2,3,6,7,8-HxCDD (hexachlorodibenzo$p$-dioxin) were detected, at concentrations of 57.16 and $13.67 \mathrm{pg} / \mathrm{g}$-lipid, respectively, followed by 1,2,3,4,6,7, 8-HpCDD and 1,2,3,7,8-PeCDD (pentachlorodibenzofuran). The concentration of 2,3,7,8-TCDD, the most toxic isomer, was $0.81 \mathrm{pg} / \mathrm{g}$-lipid. The most abundant PCDF was $2,3,4,7,8-\mathrm{PeCDF}$, at a concentration of $8.14 \mathrm{pg} / \mathrm{g}$-lipid. The levels of 2,3,7,8-TCDF, 1,2,3,4,7,8-HxCDF, 1,2,3,6,7, 8-HxCDF, 2,3,4,6,7,8-HxCDF, and 1,2,3,4,6,7,8-HpCDF ranged from 1 to $2 \mathrm{pg} / \mathrm{g}$-lipid and reflected the levels of the PCDFs-TEQ. The level of PCDDs-TEQ, 6.86 pg/g-lipidTEQ, was higher than the PCDFs-TEQ level (4.89 pg/ g-lipid-TEQ).

Relationships between newborn build and dioxin isomers in maternal breast milk

To clarify the effects of these dioxin isomers on infant growth, we examined the relationship between newborn size at birth and dioxin isomers in maternal breast milk as an indicator of maternal exposure. Table 3 shows simple 
Table 2 Levels $^{\mathrm{a}}$ of polychlorinated dibenzo- $p$-dioxins and dibenzofurans (pg/g-lipid) in 75 breast milk samples from women residing in a coastal area along the Japan Sea

\begin{tabular}{lclr}
\hline PCDDs/PCDFs & Mean (SD) & Minimum & Maximum \\
\hline PCDDs & & & \\
2,3,7,8-TCDD & $0.81(2.20)$ & 0.10 & 4.34 \\
1,2,3,7,8-PeCDD & $4.19(1.74)$ & 0.56 & 11.28 \\
$1,2,3,4,7,8-\mathrm{HxCDD}$ & $1.44(1.95)$ & 0.15 & 5.01 \\
$1,2,3,6,7,8-\mathrm{HxCDD}$ & $13.67(1.80)$ & 1.98 & 37.55 \\
$1,2,3,7,8,9-\mathrm{HxCDD}$ & $1.94(3.01)$ & 0.82 & 7.82 \\
$1,2,3,4,6,7,8-\mathrm{HpCDD}$ & $6.78(1.84)$ & 1.24 & 25.36 \\
OCDD & $56.16(1.72)$ & 14.28 & 250.04 \\
PCDFs & & & \\
2,3,7,8-TCDF & $1.02(1.82)$ & 0.10 & 3.76 \\
$1,2,3,7,8-\mathrm{PeCDF}$ & $0.29(3.92)$ & $\mathrm{ND}$ & 1.64 \\
2,3,4,7,8-PeCDF & $8.14(1.76)$ & 1.08 & 20.99 \\
$1,2,3,4,7,8-\mathrm{HxCDF}$ & $2.25(1.80)$ & 0.31 & 12.62 \\
$1,2,3,6,7,8-\mathrm{HxCDF}$ & $2.27(1.78)$ & 0.25 & 7.91 \\
$2,3,4,6,7,8-\mathrm{HxCDF}$ & $1.46(2.11)$ & 0.11 & 7.05 \\
$1,2,3,7,8,9-\mathrm{HxCDF}$ & $0.03(13.94)$ & $\mathrm{ND}$ & 0.77 \\
$1,2,3,4,6,7,8-\mathrm{HpCDF}$ & $1.19(2.95)$ & $\mathrm{ND}$ & 7.63 \\
$1,2,3,4,7,8,9-\mathrm{HpCDF}$ & $0.04(13.74)$ & $\mathrm{ND}$ & 1.57 \\
OCDF & $0.55(20.65)$ & $\mathrm{ND}$ & 11.30 \\
PCDDs-TEQ & $6.86(1.76)$ & 0.97 & 16.68 \\
PCDFs-TEQ & $4.89(1.74)$ & 0.97 & 11.96 \\
PCDDs/DFs-TEQ & $11.75(1.71)$ & 1.94 & 28.67 \\
\hline
\end{tabular}

PCDDs, Polychlorinated dibenzo- $p$-dioxins; DF, dibenzofurans; PCDFs, polychlorinated dibenzofurans; OCDD, 1,2,3,4,6,7,8,9-octachlorodibenzo- $p$-dioxin; TCDF, tetrachlorodibenzofuran; PeCDF, pentachlorodibenzofuran; HxCDD, hexachlorodibenzo- $p$-dioxin; TEQ, dioxin toxic equivalent

Mean, Geometric mean; SD, geometric standard; ND, not detectable

${ }^{a}$ Values are given in picograms per gram lipid (pg/g-lipid)

correlation coefficients by the Spearman's rho test between each dioxin isomer in breast milk versus newborn build at birth and gestational age among the 75 mother-infant pairs. A significant inverse correlation was observed between newborn length and 1,2,3,6,7,8-HxCDD $(r=-0.253$, $P<0.05)$. Moreover, newborn length showed significant inverse correlations with $2,3,4,7,8-\mathrm{PeCDF}(r=-0.307$, $P<0.01), \quad 2,3,4,6,7,8-\mathrm{HxCDF} \quad(r=-0.244, \quad P<0.05)$, and $1,2,3,4,7,8,9-\mathrm{HpCDF} \quad(r=-0.278, \quad P<0.01)$. In addition, a statistically significant negative correlation was observed between newborn length and three TEQ levels: PCDDs-TEQ $(r=-0.227, P<0.05)$, PCDFs-TEQ $(r=-0.276, \quad P<0.05)$, and total-TEQ $(r=-0.255$, $P<0.05)$. However, a significant positive correlation was observed between newborn length and 1,2,3,7,8,9-HxCDF $(r=0.238, P<0.05)$ in maternal breast milk.

Head circumference showed a significant inverse correlation only with $2,3,7,8$-TCDD $(r=-0.300, P<0.01)$.
No significant correlation was observed between any dioxin isomers and weight or chest circumference of newborns at birth.

The relationships between dioxin isomers or TEQ levels in maternal breast milk and newborn length at birth after controlling for maternal age, maternal height, infant gender and gestational age (weeks) were then investigated by multiple linear regression analysis, since maternal age was inversely correlated with newborn length $(r=-0.271$, $P<0.05)$ and gestational week $(r=-0.282, P<0.05)$ among these mother-infant pairs, and infant build is known to be related to maternal build. Smoking habit was not selected to be an explanatory factor because of the small number of smokers and the lack of difference in infant build between smokers, including ex-smokers and nonsmokers. Parity was also not included in the confounding factors because there were no significant differences in infant build and dioxin levels in breast milk between primiparas and multiparas. Dioxin level has been reported to be affected by parity in Japanese mothers, with significant decreased dioxin level of multiparas who delivered more than three babies, as compared with primiparas [13]. However, almost all multiparas were secundiparas in our study. Moreover, parity is also related to maternal age, which was known to influence dioxin levels in Japanese women[14], and was included as one of explanatory factors of the multiple regression model in this study.

As shown in Table 4, 1,2,3,6,7,8-HxCDD, 2,3,4,7,8PeCDF, 2,3,4,6,7,8-HxCDF and all three TEQ levels (PCDDs-TEQ, PCDFs-TEQ, and total-TEQ) were inversely correlated to newborn length even after adjustment for confounding factors. However, a significant correlation of $1,2,3,7,8,9-\mathrm{HxCDF}$ and $1,2,3,4,7,8,9-\mathrm{HpCDF}$ with newborn height, as estimated by the Spearman's simple correlation, was not found in the multiple linear regression analysis. Conversely, 1,2,3,7,8-PeCDD and 1,2,3,6,7,8HxCDF, which showed no significant correlation by the Spearman's rho test (Table 3), showed a significant inverse correlation to newborn length after controlling for confounding factors.

To analyze the relationships between newborn head circumference and PCDD/DF isomers in maternal breast milk, we added birth weight to the confounding variables in order to adjust for body size in multiple linear regression analyses. 2,3,7,8-TCDD was inversely related to infant head circumference at birth even after adjustment for confounding factors (Table 5).

\section{Discussion}

We found that five PCDD/DF isomers were inversely correlated with newborn length at birth after adjustment for 
Table 3 Simple correlation coefficients between newborn size and dioxin isomers in maternal breast milk among 75 Japanese mother-infant pairs

$* P<0.05, * * P<0.01$ by Spearman's rho test

Table 4 Relationships between newborn length and the PCDD/ DF isomers and TEQ levels after adjustment for confounding factors by multiple linear regression analysis

HpCDF, Heptafuran; HpCDD, heptadioxin

Covariates in the multiple regression analysis included mother's age and height, newborn gender, and gestational weeks

\begin{tabular}{|c|c|c|c|c|c|}
\hline \multirow[t]{2}{*}{ PCDDs/DFs in milk } & \multicolumn{5}{|l|}{ Birth size } \\
\hline & Length & Weight & Chest & Head & $\begin{array}{l}\text { Gestational } \\
\text { weeks }\end{array}$ \\
\hline 2,3,7,8-TCDD & -0.107 & -0.074 & 0.069 & $-0.300 * *$ & -0.058 \\
\hline 1,2,3,7,8-PeCDD & -0.195 & 0.027 & 0.153 & -0.115 & 0.021 \\
\hline 1,2,3,4,7,8-HxCDD & -0.132 & 0.062 & 0.153 & -0.020 & 0.081 \\
\hline $1,2,3,6,7,8-\mathrm{HxCDD}$ & $-0.253^{*}$ & -0.069 & 0.085 & -0.180 & -0.054 \\
\hline 1,2,3,7,8,9-HxCDD & -0.141 & 0.025 & 0.128 & -0.048 & 0.024 \\
\hline $\begin{array}{c}1,2,3,4,6,7,8- \\
\text { HxCDD }\end{array}$ & -0.141 & 0.025 & 0.128 & -0.048 & 0.024 \\
\hline OCDD & -0.064 & 0.045 & 0.163 & -0.167 & 0.090 \\
\hline $2,3,7,8-\mathrm{TCDF}$ & 0.161 & 0.173 & 0.176 & 0.088 & -0.001 \\
\hline $1,2,3,7,8-\mathrm{PeCDF}$ & -0.011 & -0.044 & 0.102 & -0.082 & 0.073 \\
\hline $2,3,4,7,8-\mathrm{PeCDF}$ & $-0.307 * *$ & -0.110 & 0.013 & -0.185 & -0.088 \\
\hline 1,2,3,4,7,8-HxCDF & -0.094 & -0.016 & 0.081 & -0.155 & 0.051 \\
\hline $1,2,3,6,7,8-\mathrm{HxCDF}$ & -0.151 & -0.091 & 0.067 & -0.157 & 0.105 \\
\hline 2,3,4,6,7,8-HxCDF & $-0.244 *$ & -0.098 & 0.082 & -0.158 & 0.090 \\
\hline 1,2,3,7,8,9-HxCDF & $0.238^{*}$ & -0.001 & 0.008 & 0.125 & 0.025 \\
\hline $\begin{array}{c}1,2,3,4,6,7,8- \\
\mathrm{HxCDF}\end{array}$ & 0.120 & 0.157 & 0.218 & 0.005 & 0.103 \\
\hline $\begin{array}{c}1,2,3,4,7,8,9- \\
\mathrm{HxCDF}\end{array}$ & $-0.278^{* *}$ & 0.145 & 0.086 & 0.159 & 0.207 \\
\hline OCDF & 0.170 & 0.027 & -0.094 & -0.051 & 0.082 \\
\hline PCDDs-TEQ & -0.227 & -0.030 & 0.124 & -0.170 & -0.011 \\
\hline PCDFs-TEQ & $-0.276^{*}$ & 0.095 & 0.019 & 0.174 & -0.066 \\
\hline PCDDs/DFs-TEQ & $-0.255^{*}$ & -0.056 & 0.081 & -0.181 & -0.043 \\
\hline
\end{tabular}

\begin{tabular}{llll}
\hline PCDDs/DFs in milk & $\begin{array}{l}\text { Beta coefficient } \\
\text { (SE) }\end{array}$ & $\begin{array}{l}\text { Standardized } \\
\text { coefficient }\end{array}$ & $\begin{array}{l}P \\
\text { value }\end{array}$ \\
\hline $2,3,7,8-\mathrm{TCDD}$ & $-0.595(0.594)$ & -0.101 & 0.320 \\
$1,2,3,7,8-\mathrm{PeCDD}$ & $-1.793(0.829)$ & -0.215 & 0.034 \\
$1,2,3,4,7,8-\mathrm{HxCDD}$ & $-0.513(0.714)$ & -0.074 & 0.475 \\
$1,2,3,6,7,8-\mathrm{HxCDD}$ & $-2.086(0.789)$ & -0.265 & 0.010 \\
$1,2,3,7,8,9-\mathrm{HxCDD}$ & $0.763(0.607)$ & -0.129 & 0.213 \\
$1,2,3,4,6,7,8-$ & $-1.157(0.758)$ & -0.153 & 0.132 \\
HpCDD & & & \\
OCDD & $0.779(0.876)$ & -0.091 & 0.377 \\
$2,3,7,8-\mathrm{TCDF}$ & $0.910(0.761)$ & 0.118 & 0.236 \\
$1,2,3,7,8-\mathrm{PeCDF}$ & $-0.376(0.029)$ & -0.016 & 0.875 \\
$2,3,4,7,8-\mathrm{PeCDF}$ & $-1.744(0.127)$ & -0.212 & 0.038 \\
$1,2,3,4,7,8-\mathrm{HxCDF}$ & $-1.003(0.085)$ & -0.127 & 0.206 \\
$1,2,3,6,7,8-\mathrm{HxCDF}$ & $-1.980(0.792)$ & -0.245 & 0.015 \\
$2,3,4,6,7,8-\mathrm{HxCDF}$ & $-1.493(0.028)$ & -0.241 & 0.016 \\
$1,2,3,7,8,9-\mathrm{HxCDF}$ & $7.750(0.127)$ & 0.162 & 0.115 \\
$1,2,3,4,6,7,8-\mathrm{HpCDF}$ & $0.229(0.044)$ & 0.070 & 0.502 \\
$1,2,3,4,7,8,9-\mathrm{HpCDF}$ & $3.649(3.451)$ & 0.111 & 0.294 \\
OCDF & $-0.451(0.384)$ & -0.113 & 0.244 \\
PCDDs-TEQ & $-1.925(0.829)$ & -0.230 & 0.023 \\
PCDFs-TEQ & $-1.725(0.849)$ & -0.202 & 0.046 \\
PCDDs/DFs-TEQ & $-1.908(0.858)$ & -0.220 & 0.029 \\
\hline
\end{tabular}


Table 5 Relationships between newborn head circumference and the PCDD/DF isomers and TEQ levels in breast milk after adjustment for confounding factors by multiple linear regression analysis

\begin{tabular}{llll}
\hline PCDDs/DFs in milk & $\begin{array}{l}\text { Beta coefficient } \\
\text { (SE) }\end{array}$ & $\begin{array}{l}\text { Standardized } \\
\text { coefficient }\end{array}$ & $\begin{array}{l}P \\
\text { value }\end{array}$ \\
\hline $2,3,7,8-$ TCDD & $-0.891(0.352)$ & -0.220 & 0.014 \\
$1,2,3,7,8-$ PeCDD & $-0.736(0.520)$ & -0.128 & 0.161 \\
$1,2,3,4,7,8-H x C D D$ & $-0.115(0.442)$ & -0.024 & 0.796 \\
$1,2,3,6,7,8-H x C D D$ & $-0.606(0.505)$ & -0.112 & 0.235 \\
$1,2,3,7,8,9-H x C D D$ & $-0.144(0.379)$ & -0.380 & 0.705 \\
$1,2,3,4,6,7,8-$ & $-0.773(0.466)$ & -0.148 & 0.102 \\
HpCDD & & & \\
OCDD & $-0.325(0.544)$ & -0.055 & 0.552 \\
$2,3,7,8-$ TCDF & $-0.061(0.480)$ & -0.011 & 0.899 \\
$1,2,3,7,8-$ PeCDF & $-1.149(1.467)$ & -0.071 & 0.436 \\
$2,3,4,7,8-\mathrm{PeCDF}$ & $-0.754(0.519)$ & -0.101 & 0.273 \\
$1,2,3,4,7,8-\mathrm{HxCDF}$ & $-0.606(0.486)$ & -0.112 & 0.216 \\
$1,2,3,6,7,8-\mathrm{HxCDF}$ & $-0.393(0.510)$ & -0.071 & 0.444 \\
$2,3,4,6,7,8-\mathrm{HxCDF}$ & $-0.166(0.392)$ & -0.039 & 0.673 \\
$1,2,3,7,8,9-\mathrm{HxCDF}$ & $2.128(3.307)$ & 0.065 & 0.486 \\
$1,2,3,4,6,7,8-\mathrm{HpCDF}$ & $-0.234(0.273)$ & -0.079 & 0.393 \\
$1,2,3,4,7,8,9-\mathrm{HpCDF}$ & $0.892(2.141)$ & 0.039 & 0.678 \\
OCDF & $-0.002(0.096)$ & -0.002 & 0.983 \\
PCDDs-TEQ & $-0.861(0.520)$ & -0.150 & 0.102 \\
PCDFs-TEQ & $-0.623(0.534)$ & -0.106 & 0.247 \\
PCDDs/DFs-TEQ & $-0.812(0.538)$ & -0.136 & 0.136 \\
\hline & & & \\
\hline
\end{tabular}

Although previous epidemiological studies have reported associations between decreased birth weight and lowdose exposure to PCDDs/DFs during pregnancy [7], we did not find any association of PCDD/DF isomers with newborn weight. In addition to the birth weight, newborn length at birth is a powerful parameter of fetal growth. It has become evident recently that short length at birth may lead to stunting during childhood, which increases the risk of poor school performance and poor physical activity [17]. Therefore, our results of an association between newborn length at birth and total TEQ of dioxins suggest that maternal exposure to dioxins affects fetal linear growth and possibly development during infancy and childhood. Nakajima et al. [18] reported that the total PCDD level in maternal plasma during pregnancy was associated with a decreased mental development score in 6-month-old infants in a Japanese cohort, suggesting that total dioxin levels may influence infant development after birth. Moreover, birth length is also known to be a predictive indicator of adult height [19], and short height in adulthood can be a risk factor for death from cardiovascular and other diseases [20]. Therefore, the effect of dioxins on newborn length may lead to poor health not only in childhood but also in adulthood, indicating that the maternal environment should be improved to decrease dioxin exposure during pregnancy.

The dioxin congener pattern in the breast milk of our subjects was similar to that reported in residents of urban 
cities, such as Saitama [21], Tokyo [22], and Osaka [23], who were mainly contaminated by consuming contaminated food, indicating that food was an important source of dioxin contamination in these subjects. In particular, the first to second trimester of pregnancy may be a sensitive period for dioxin exposure because newborn length at birth is associated with maternal weight gain, which is in turn related to maternal nutritional status during these trimesters [17]. It is believed that seafood is a major source of exposure to dioxins, and populations with a high intake of fish, especially fish with a high fat content, and living on the coast or in bays are at high risk of contamination. The answers to a food frequency questionnaire we carried out in an earlier study revealed an association between mothers with a higher estimated fish intake and higher 2,3,7,8TCDD levels in their breast milk [24]. The data of that survey also suggested that a large intake of vegetables and fruits resulted in an increased exposure to dioxin, as the PCDFs-TEQ in breast milk was higher in mothers who ate fruit every day, and the levels of $1,2,3,6,7,8-\mathrm{HxCDD}$ and 2,3,4,7,8-PCDF in breast milk were higher in mothers who had large servings of yellow-green vegetables [24]. Thus, not only consumers of fat-rich animal food but also those of agriculture products might be at risk of exposure to/ intake of dioxins from the general environment; in particular, Japanese rural areas, such as the area covered in our study, have a greater chance of being exposed to agricultural chemicals.

Head circumference at birth is another parameter of fetal growth, but can be changed independently of weight and height. Continued smoking at a relatively high level throughout pregnancy [25] and poor nutritional status, such as -3 polyunsaturated fatty acid and zinc deficiency during pregnancy [26, 27], have been reported to induce a disproportionate decrease in newborn head circumference at birth. Fein et al. [28] investigated the effects of maternal exposure to heavy PCBs exposure on fetal growth due to the consumption of contaminated fish in Lake Michigan, USA, and found disproportionately smaller head circumference in relation to birth weight in infants whose mothers had $15 \mathrm{pg} / \mathrm{g}$-lipid or more PCBs in their serum, as compared with the infants of mothers with $\mathrm{PCBs}<15 \mathrm{pg} / \mathrm{g}$ lipid. However, head circumference has not been used as an index of fetal growth in previous studies of infants exposed to PCDDs/PCDFs [7, 29], with the exception of a previous study carried out by our group which reported that the concentration of 2,3,7,8-TCDD negatively correlates with newborn head circumference without any associations between 2,3,7,8-TCDD and other parameters of infant build [30]. The present study confirmed this result in a large number of the subjects.

2,3,7,8-Tetrachlorodibenzo- $p$-dioxin is the most toxic isomer of the dioxins, and several animal studies have demonstrated that maternal exposure to 2,3,7,8-TCDD affects neurodevelopment and induces neuro-behavioral alterations in offspring rats, such as working memory in a radial arm maze [31], operant responding in running wheels or two-lever chamber [32], and discriminationreversal learning [33]. We have also reported that maternal exposure to $2,3,7,8$-TCDD during pregnancy significantly delays fetal brain growth and affects the active avoidance behavior of rat offspring during the growth period [34]. In particular, we found a developmental delay in the forebrain, which suggests that 2,3,7,8TCDD affects the limbic system, which in turn plays an important role in avoidance behaviors [34]. A functional change in the limbic system can induce not only learning deficits but also emotional disturbances, and 2,3,7,8TCDD may therefore affect both the emotional development and cognitive development of the human infant. A well-designed epidemiological study to investigate cognitive and emotional development is necessary in the future to clarify the effects of $2,3,7,8$-TCDD on brain development in human infants.

Acknowledgments We are particularly grateful for the assistance of Mr. Masahiro Watanabe and all the staff at the AI Group of Nagoya Center of JEOL DATUM LTD, and Mr. Kenji Matsuura and Mr. Noriyuki Yahata at the International Technical \& Training Center, AI Technical Division of JEOL DATUM LTD for their co-operation in improving the HR-GC/MS environment for measuring PCDDs/DFs. We also thank Ms. Chiharu Nakano for her extensive assistance with the dioxins analyses. Finally, we are most grateful for the co-operation of the volunteer mothers and hospital staff. This work was supported by a grant for Project Research from the High-Technology Center of Kanazawa Medical University (H2000-4, H2005-9).

\section{References}

1. Pesatori AC, Consonni D, Bachetti S, Zocchetti C, Bonzini M, Baccarelli A, et al. Short- and long-term morbidity and mortality in the population exposed to dioxin after the "Seveso accident". Ind Health. 2003;41:127-38.

2. Mocarelli P, Brambilla P, Gerthoux PM, Patterson DG, Needham LL. Change in sex ratio with exposure to dioxin. Lancet. 1996;348:409.

3. Needham LL, Gerthoux PM, Patterson DG, Brambilla P, Turner WE, Beretta C, et al. Serum dioxin levels in Seveso, Italy, population in 1976. Teratog Carcinog Mutagen. 1997;17:225-40.

4. Ngo AD, Taylor R, Roberts CL, Nguyen TV. Association between Agent Orange and birth defects: systematic review and meta-analysis. Int J Epidemiol. 2006;35:1220-30.

5. Rogan WJ, Gladen BC, Hung KL, Koong S, Shin L, Taylor J. Congenital poisoning by polychlorinated biphenyls and their contaminations in Taiwan. Science. 1998;241:334-6.

6. Chen YJ, Guo YL, Hsu C. Cognitive development of children prenatally exposed to polychlorinated biphenyls (Yu-Cheng children) and their siblings. J Formos Med Assoc. 1992;91:704-7.

7. Patandin S, Koopman-Esseboom C, De Ridder MAJ, WeisglasKuperus N, Sauer PJJ. Effects of environmental exposure to polychlorinated biphenyls and dioxins on birth size and growth in Dutch children. Pediatr Res. 1998;44:538-45. 
8. Hachy DL, Thomas MR, Emken EA, Garza C, Brown-Booth L, Adlof RO, et al. Human lactation: maternal transfer of dietary triglycerides labeled with stable isotopes. J Lipid Res. 1987;21:1185-92.

9. Pluim HJ, Boersma ER, Kramer I, Olie K, van der Slikke JW, Koppe JG. Influence of short-term dietary measures on dioxin concentrations in human milk. Environ Health Perspect. 1994;102:968-71.

10. Patterson DG Jr, Holler JS, Belser E, Booser EL, Lapeza CR, Needham LL. Determination of 2,3,7,8-tetrachlorodibenzo- $p$ dioxin (TCDD) in human adipose tissue on whole-weight and lipid bases. Chemosphere. 1987;16:935-6.

11. Tawara K, Honda R, Nishijo M, Nakagawa H. Pretreatment procedure of dioxin analysis for a small volume of human breast milk. J Kanazawa Med Univ. 2003;28:17-25.

12. Van den Berg M, Birnbaum L, Bosveld AT, Brunstrom B, Cook P, Feeley M, et al. Toxic equivalency factors (TEFs) for PCBs, PCDDs, PCDFs for humans and wildlife. Environ Health Perspect. 1998;106:775-92.

13. Iida $T$, Hirakawa $H$, Matsueda $T$, Takenaka $S$, Nagayama $J$. Polychlorinated dibenzo- $p$-dioxins and related compounds in breast milk of Japanese primiparas and multiparas. Chemosphere. 1999;38:2461-6.

14. Tajimi M, Watanabe M, Oki I, Ojima T, Nakamura Y. PCDDs, PCdfs and Co-PCBs in human breast milk samples collected in Tokyo, Japan. Acta Paediatr. 2004;93:1098-102.

15. McLennan JE, Gilles FH, Neff RK. A model of growth of the human fetal brain. In: Gilles FH, Leviton A, Dooling EC, editors. The developing human brain: growth and epidemiologic neuropathy. Boston: John Wright P.S.G. Inc; 1983. p. 43-58.

16. Ministry of Health, Labour and Welfare. Report of Infant Children Growth Surveillance in 2000. Tokyo, October, 2001. Available at: http://www.mhlw.go.jp/houdou/0110/h1024-4.html.

17. Neufeld LN, Haas JD, Grajeda R, Martorell R. Changes in maternal weight from the first to second trimester of pregnancy are associated with fetal growth and infant length at birth. Clin Nutr. 2004;79:646-52.

18. Nakajima S, Saijo Y, Kato S, Sasaki S, Uno A. Effects of prenatal exposure to polychlorinated biphenyls and dioxins on mental and motor development in Japanese children at 6 months of age. Environ Health Perspect. 2006;114:773-8.

19. Sorensen HT, Sabroe S, Rothman KJ. Birth weight and length as predictors for adult height. Am J Epidemiol. 1999;149:726-9.

20. Marmot MG, Shipley MJ, Rose G. Inequality in death-specific explanations of general pattern? Lancet. 1984;1(8384):1003-6.

21. Takekuma M, Saito K, Ogawa M, Matumoto R, Kobayashi S. Levels of PCDDs, PCDFs and Co-PCBs in human milk in Saitama, Japan, and epidemiological research. Chemosphere. 2004:54:127-35.

22. Tajimi M, Uehara R, Watanabe M, Oki I, Ojima T, Nakamura Y. Correlation coefficients between the dioxin levels in mother's milk and the distances to the nearest waste incinerator which was the largest source of dioxins from each mother's place of residence in Tokyo, Japan. Chemosphere. 2005;61:1256-62.

23. Nakatani T, Okazaki K, Ogaki S, Itano K, Fujita T, Kuroda K, et al. Polychlorinated dibenzo- $p$-dioxins, polychlorinated dibenzofurans, and coplanar polychlorinated biphenyls in human milk in Osaka City, Japan. Arch Environ Contam Toxicol. 2005;49:131-40.

24. Tawara K, Nishijo M, Honda R, Nakagawa H, Seto T, Kido T. Relationship between food preference in women and PCDDs/DFs levels in breast milk in the northern district of Japan. Organohalogen Compd. 2007;69:2031-3.

25. Lindley AA, Becker S, Gray RH, Herman AA. Effects of continuing or stopping smoking during pregnancy on infant birth weight, crown-heel length, head circumference, ponderal index, and brain:body weight ratio. Am J Epidemiol. 2000;152:219-25.

26. Szajewska K, Horvath A, Koletzka B. Effect of -3 long-chain polyunsaturated fatty acid supplementation of women with lowrisk pregnancies on pregnancy outcomes and growth measures at birth: a meta-analysis of randomized controlled trials. Am J Clin Nutr. 2006;83:1337-44.

27. Lagiou P, Mucci L, Tamimi R, Kuper H, Lagiou A, Hsieh CC. Micronutrient intake during pregnancy in relation to birth size. Eur J Nutr. 2005;44:52-9.

28. Fein GG, Jacobson JL, Jacobson SW, Schwartz PM, Dowler JK. Prenatal exposure to polychlorinated biphenyls: effects on birth size and gestational age. J Pediatr. 1984;105:315-20.

29. Lin CM, Li CY, Mao IF. Birth outcomes of infants born in areas with elevated ambient exposure to incinerator generated PCDD/ Fs. Environ Int. 2006;32:624-9.

30. Nishijo M, Tawara K, Nakagawa H, Honda R, Kido T, Nishijo H, et al. 2, 3, 7, 8-Tetrachlorodibenzo- $p$-dioxin in maternal breast milk and newborn head circumference. J Expos Sci Environ Epidemiol. 2008;18:246-51.

31. Seo BW, Sparks AJ, Medra K, Amin S, Schantz SL. Learning and memory in rats gestationally and lactationally exposed to $2,3,7,8$ tetrachlorodibenzo- $p$-dioxin (TCDD). Neurotoxicol Teratol. 1999;21:231-9.

32. Markowski VP, Zareba G, Stern S, Cox C, Weiss B. Impaired operant responding to motor reinforcement and the determination of benchmark dosed following perinatal exposure to low-level 2, 3, 7, 8-tetrachlorodibenzo- $p$-dioxin. Environ Health Perspect. 2001;109:621-7.

33. Markowski VP, Cox C, Preston R, Weiss B. Impaired cued delayed alternation behavior in adult rat offspring following exposure to 2,3,7,8-tetrachlorodibenzo- $p$-dioxin on gestation day 15. Neurotoxicol Teratol. 2002;24:209-18.

34. Nishijo M, Kuriwaki J, Hori E, Tawara K, Nakagawa H, Nishijo $H$. Effects of maternal exposure to 2,3,7,8-tetrachlorodibenzo- $p$ dioxin on fetal brain growth and motor and behavioral development in offspring rats. Toxicol Lett. 2007;173:41-7. 